\title{
DOS NUEVAS ESPECIES DE HECHTIA (BROMELIACEAE) DE MÉXICO
}

\author{
Adolfo Espejo-Serna ${ }^{1}$, Ana Rosa López-Ferrari ${ }^{1}$, Ivón Ramírez-Morilloº y \\ NANCy MartíneZ-CorreA ${ }^{1}$
}

${ }^{1}$ Universidad Autónoma Metropolitana-Iztapalapa, División de Ciencias Biológicas

y de la Salud, Departamento de Biología, Herbario Metropolitano, 09340 México, D.F. aes@xanum.uam.mx

${ }^{2}$ Centro de Investigación Científica de Yucatán, A.C., Herbario CICY, Calle 43

Núm. 130, Colonia Chuburná de Hidalgo, 97200 Mérida, Yucatán

ramirez@cicy.mx

\section{RESUMEN}

Se describen e ilustran Hechtia nuusaviorum y H. perotensis. La primera es una especie endémica de Oaxaca y la segunda se conoce de los estados de Veracruz y de Puebla, de la región conocida como Valle de Perote.

Palabras clave: Bromeliaceae, Hechtia, México, Oaxaca, Puebla, Veracruz.

\section{ABSTRACT}

Hechtia nuusaviorum and $H$. perotensis are described and illustrated. The former is a species endemic to Oaxaca and the second is known from Veracruz and Puebla states, from the region known as Valle de Perote.

Key words: Bromeliaceae, Hechtia, Mexico, Oaxaca, Puebla, Veracruz.

Luther (2006) cita para el género Hechtia Klotzsch un total de 48 especies, de las cuales todas se encuentran presentes en México, con excepción de tres: $H$. dichroantha Donn. Sm., H. guatemalensis Mez y H. malvernii Gilmartin. Por otra parte, Espejo y López-Ferrari (1994) y Espejo et al. (2004) registran para el país 48 especies, lo que sumado a las tres antes mencionadas hace un total de 51 para el género. Existen además varios taxa sin describir, lo cual aumentará considerablemente esta cifra. 
Hechtia se distribuye desde el sur de Texas hasta el norte de Nicaragua, siendo México su centro de diversificación, con $94.1 \%$ de sus taxa hasta ahora descritos. Sus representantes crecen principalmente en regiones áridas y semiáridas de todo el país y constituyen en algunos casos extensos matorrales rosetófilos.

De las 48 especies presentes en México (Espejo et al., 2004), 46 son endémicas, es decir $90.1 \%$ del género y $95.8 \%$ de las citadas para la República. Cabe señalar, que si nos ajustamos a los criterios propuestos por Rzedowski (1991a; 1991b) en sus análisis sobre la diversidad, orígenes y endemismo de la flora fanerogámica mexicana, el porcentaje de endemitas de Hechtia alcanzaría 100\% para Megaméxico 1, 96\% para Megaméxico 2 y 100\% para Megaméxico 3.

La taxonomía del género es complicada debido a la escasez de material de referencia, ya que las colecciones son fragmentarias y a menudo constituidas por individuos de un solo sexo. Lo anterior se debe a varios factores, entre los que podemos mencionar lo agreste del hábitat en donde crecen, lo agresivo de sus hojas espinosas y lo corto de su temporada de floración. Todos estos factores se han traducido en problemas para reconocer y/o delimitar los taxa del género y en el desconocimiento casi total de la biología de los mismos.

Como parte del trabajo de recolección para el proyecto Flora Bromeliológica Mexicana, hemos detectado varias poblaciones del género que corresponden, sin duda, a especies no descritas, por lo cual proponemos:

Hechtia nuusaviorum Espejo \& López-Ferrari, sp. nov. (Figs. 1, 2 y 3).

Herbae rosulatae, usque ad $2 \mathrm{~m}$ altae; caulis brevis rarius elongatus, crassus, lignosus, ad $30 \mathrm{~cm}$ diametro et $1.2 \mathrm{~m}$ longus; folia permulta, carnosa, mollia, lamina citrus-viridis, 30-75 cm longa, supra glabra, subtus lepidota, margine spinas gerens; spinae rectae vel recurvatae, 4-9 $\mathrm{mm}$ longae, axillae albo-lepidotae. Inflorescentiae laterales, erectae, bis ramosae; spicae masculinae oblongo-cylindricae, 2.4-3.2 cm longae, 1.5-2 cm diametro; spicae femineae globosae, 1.2-1.4 cm diametro. Flores masculini albi, petala elliptica vel oblonga, 6-6.3 mm longa, 2.2-2.4 mm lata, filamenta linearia, 5.5-6.1 mm longa, antherae flavae, oblongae, ca. $1.4 \mathrm{~mm}$ longae. Flores feminei albo-rosei, petala elliptica, 6-7 mm longa, 3.5-3.8 mm lata; staminodia alba, triangularia, ca. $3.8 \mathrm{~mm}$ longa, antherae absentes, ovarium ovoideum, roseum. Spicae in fructu globosae, capsula ovoidea, atrobrunnea, nitida.

Hierbas arrosetadas, rupícolas, en flor de hasta $2 \mathrm{~m}$ de alto, las rosetas compactas, de hasta $75 \mathrm{~cm}$ de alto y $50 \mathrm{~cm}$ de diámetro, solitarias o en grupos pequeños; 
Espejo et al.: Dos nuevas especies de Hechtia de México

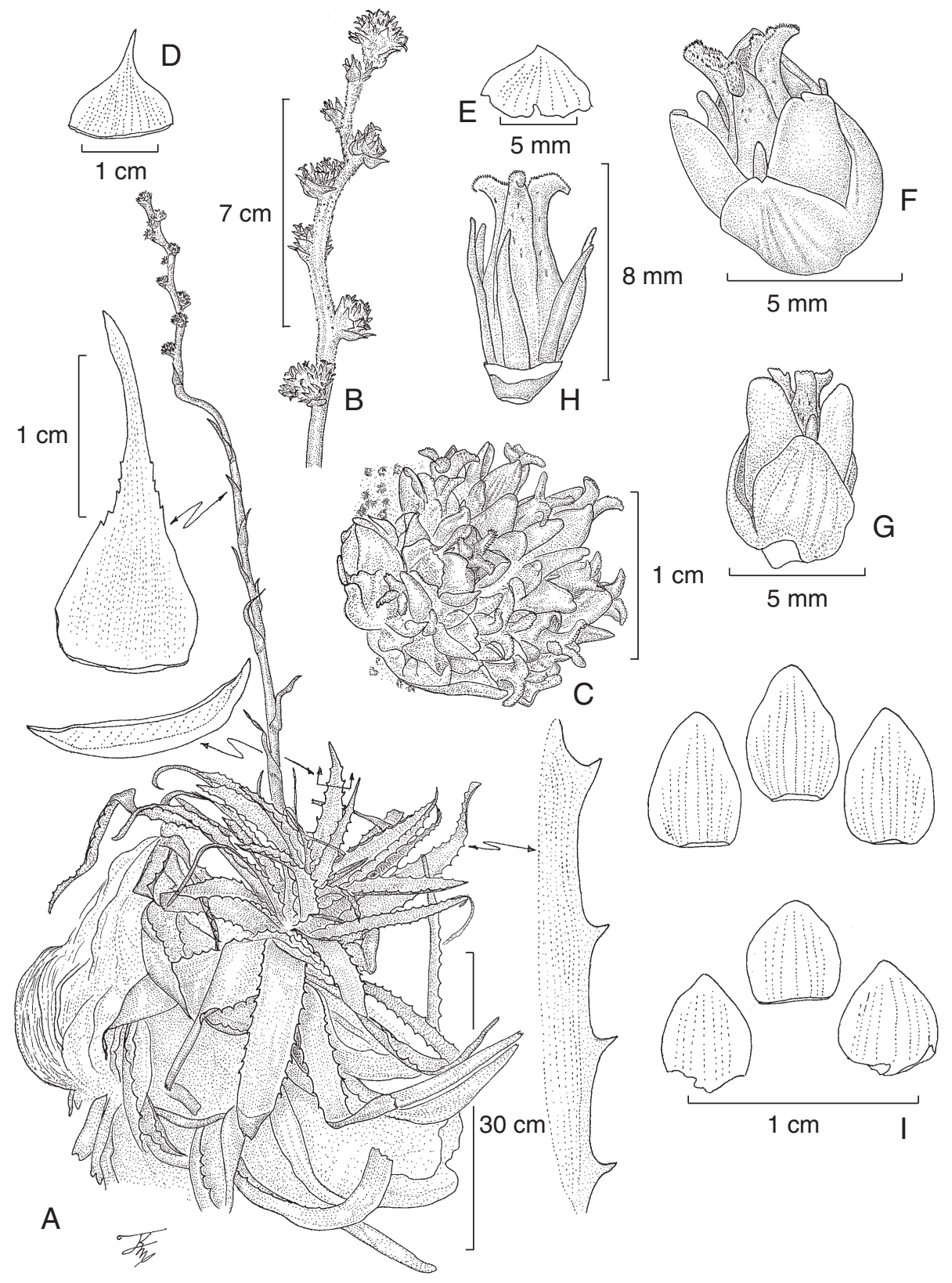

Fig. 1. Hechtia nuusaviorum Espejo \& López-Ferrari. A. hábito; B. inflorescencia; C. espiga; D. bráctea primaria; E. bráctea floral; F y G. flor; H. flor sin perianto; I. flor disecada. Planta femenina, basado en J. Ceja et al. 1751. 

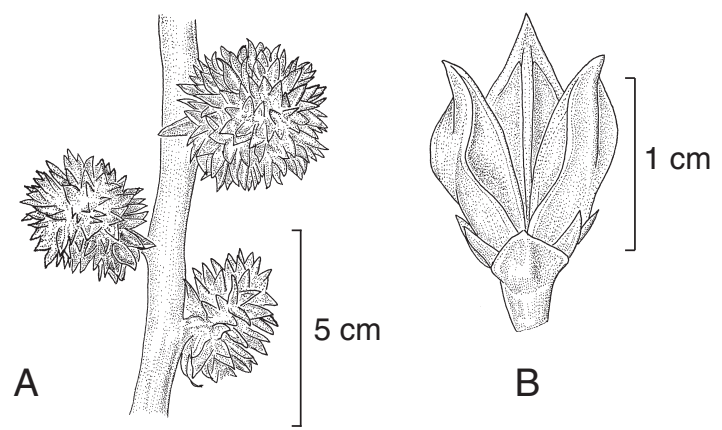

B

Fig. 2. Hechtia nuusaviorum Espejo \& López-Ferrari. A. espigas maduras; B. cápsula abierta. (Planta femenina, basado en J. Ceja et al. 1751)

tallos conspicuos, crasos, leñosos, de 15 o $30 \mathrm{~cm}$ de diámetro y de hasta $1.2 \mathrm{~m}$ de largo. Hojas numerosas, carnosas, suaves, las vainas pardas claras, anchamente ovadas a subcuadradas, de 3.5-8.5 cm de largo, 3.5-7.5 cm de ancho, lustrosas, blanco-lepidotas especialmente en la superficie abaxial, las láminas de color verde limón, largamente triangulares, de 30-75 cm de largo, 1.5-4.5 cm de ancho, glabras en la haz, lepidotas en el envés, espinosas en el margen, agudas, apiculadas y pungentes en el ápice, las espinas rectas a curvadas, verdes a pardas, de 4-9 mm de largo, separadas entre sí 1-2 cm, con escamas blancas en las axilas. Inflorescencias laterales, erectas, compuestas, paniculadas; las masculinas de 1.2-1.3 m de alto, 2 veces ramificadas, con numerosas espigas, el escapo cilíndrico, de 30-40 cm de largo, 1.4-2.5 cm diámetro, el raquis flexuoso; brácteas del escapo pardas, triangulares, de $2.2-20 \mathrm{~cm}$ de largo, 1.5-3.5 cm de ancho, agudas a acuminadas, las basales densamente imbricadas y mucho más largas que los entrenudos, las apicales más cortas que los entrenudos, las vainas enteras, las láminas erosas a espinosas en el margen, densamente lepidotas en la base en el envés, glabrescentes en la haz, las espigas densas, oblongo-cilíndricas, de 2.4-3.2 cm de largo, de 1.5-2 cm de diámetro; brácteas primarias pardas claras, ovado-triangulares, de $1.5-3 \mathrm{~cm}$ de largo, $1-1.5 \mathrm{~cm}$ de ancho, lepidotas en el envés, erosas, acuminadas; brácteas florales pardas claras, ovadas a ovado-triangulares, de 5-6 mm de largo, de 4-5 mm de ancho; flores polísticas, divaricadas, densamente dispuestas, numerosas por espiga, actinomorfas, sésiles; sépalos libres, pardos claros, ovados, de 4-4.7 mm de largo, de 2.3-2.4 $\mathrm{mm}$ de ancho, agudos en el ápice, conspicuamente nervados; pétalos libres, blancos, elípticos a oblongos, de 6-6.3 mm de largo, de 2.2-2.4 mm de ancho, agudos en el ápice; estambres subiguales, casi tan largos como los pétalos, los filamentos lineares, de 5.5-6.1 mm de largo, las anteras amarillas, oblongas, de ca. 1.4 mm de largo; ovario vestigial, abortivo; las femeni- 

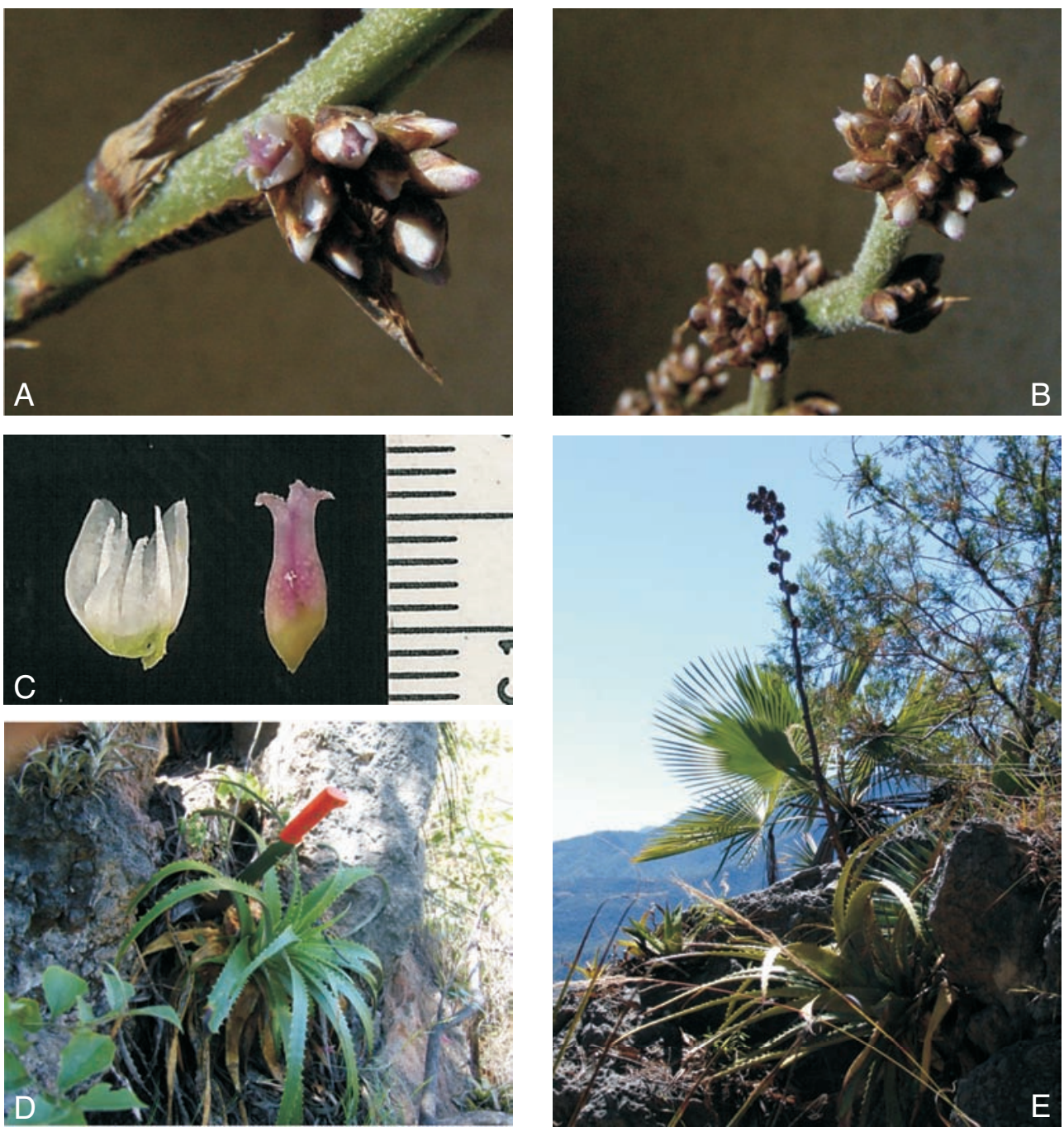

Fig. 3. Hechtia nuusaviorum Espejo \& López-Ferrari. A y B. espigas con flores en antesis; C. flor disecada; D y E. hábito. Planta femenina, J. Ceja et al. 1751, fotos A. Espejo.

nas de 0.8-2 m de alto, 2-pinnadas, con numerosas espigas, el escapo cilíndrico, de hasta $65 \mathrm{~cm}$ de largo, por 1-1.5 cm de diámetro, verde, floculoso; brácteas del escapo pardas claras, cartáceas, triangulares, de 2.5-10 cm de largo, de 6-12 mm de ancho, tan largas o ligeramente más largas que los entrenudos, disminuyendo gradualmente de tamaño hacia el ápice, las espigas difusas a ascendentes, globosas, una por nudo, de 1.2-1.4 cm de diámetro; brácteas primarias ovadas a suborbiculares, pardas, de 
ca. $1.3 \mathrm{~cm}$ de largo por ca. $1 \mathrm{~cm}$ de ancho, prominentemente nervadas, acuminadas a agudas, cuspidadas; brácteas florales pardas, anchamente ovadas, de 5-7 mm de largo por ca. $5 \mathrm{~mm}$ de ancho, enteras, glabras; flores polísticas, densamente dispuestas, ca. 20 por espiga, actinomorfas, sésiles; sépalos ovados, agudos y apiculados, de 4.7-5 mm de largo por ca. $4.3 \mathrm{~mm}$ de ancho, pardos con los márgenes blancos con puntos rosados; pétalos elípticos, de 6-7 mm de largo, por 3.5-3.8 mm de ancho, agudos, blancos con puntos rosados a lo largo del nervio medio; ovario ovoide, de 7-7.7 mm de largo por ca. $2.6 \mathrm{~mm}$ de diámetro, rosado, estigmas tres, papilosos; estaminodios 6, triangulares, de ca. $3.8 \mathrm{~mm}$ de largo, blancos, sin anteras. Cápsula parda, lustrosa, ovoide, de ca. $1 \mathrm{~cm}$ de largo, de $5 \mathrm{~mm}$ de diámetro; semillas pardas oscuras, fusiformes, falcadas, de ca. $6 \mathrm{~mm}$ de largo por ca. $1.3 \mathrm{~mm}$ de diámetro, bicaudadas.

Tipo: México, Oaxaca, distrito de Tlaxiaco, municipio de Santiago Yosondúa, ca. $4 \mathrm{~km}$ después de Santiago Yosondúa, rumbo a Yerba Santa, en las cascadas, 1650'43" N, 97³4'52" W, 1990 m s.n.m., riscos en bosque de pino-encino con algunos elementos mesófilos, 11 nov. 2005, J. Ceja, A. Espejo, A. R. López-Ferrari, A. Mendoza R. \& G. Carnevali 1751 (holotipo, UAMIZ(x6), planta femenina).

Paratipos: México, Oaxaca, distrito de Tlaxiaco, municipio de Santiago Yosondúa, ca. 4 km después de Santiago Yosondúa, rumbo a Yerba Santa, en las cascadas, 1650'43" N, 97³4'52" W, 1990 m s.n.m., riscos en bosque de pino-encino con algunos elementos mesófilos, 11 nov. 2005, G. Carnevali, A. Espejo, A. R. LópezFerrari, J. Ceja \& A. Mendoza R. 7135 (CICY, planta femenina); a 4 km al S de Yosondúa, camino a Yerba Santa, ladera rocosa caliza con aglomerados y de 90 grados de inclinación con matorral rosetófilo con Agave dasylirioides, A. seemanniana, A. angustiarum, Dasylirion serratifolium y Hechtia, 1650' N, 97³5" W, 1700 m s.n.m., A. García-Mendoza, A. de Ávila, L. Cervantes \& A. Saynes 6841 (MEXU, planta femenina); 6843 (MEXU, planta masculina); ranchería Yerba Santa, paraje Quavendigui, at the overlook at the cross at the water falls, 16³' N, 97²34' W, 1930 m s.n.m., Quercus-Pinus-Juniperus forest with Agave spp. and bromeliads, B. \& K. Benz, B. Hallberg \& M. Burd 679 (MEXU, XAL, planta femenina).

Hechtia nuusaviorum se reconoce por sus inflorescencias femeninas con las espigas globosas (Figs. 1, 2 y 3) con flores blanco-rosadas, por sus hojas muy suaves y carnosas de color verde limón y por sus tallos conspicuos de más de $15 \mathrm{~cm}$ de diámetro, caracteres que la diferencian de todas las demás especies del género. Por sus espigas cortas y compactas y sus infrutescencias globosas, $H$. nuusaviorum po- 
dría aparentemente ubicarse en el "grupo" de H. glomerata, sin embargo los caracteres vegetativos y florales del taxon aquí propuesto son totalmente diferentes de cualquier otra especie del género. No existe hasta el momento una clasificación infragenérica formal de Hechtia, pero sospechamos que $H$. nuusaviorum se ubicaría en una sección propia.

Distribución y habitat. Hechtia nuusaviorum se conoce únicamente de la localidad tipo, en donde crece como rupícola sobre riscos en bosques de pino-encino con algunos elementos mesófilos entre los 1700 y los 1900 m s.n.m.

Etimología. El epíteto específico hace referencia al pueblo mixteco, "Ñuu Savi", "pueblo de las nubes" o "pueblo de la lluvia", una de las etnias más ricas e interesantes culturalmente hablando del estado de Oaxaca, región de la cual procede la planta aquí descrita.

Por otra parte, en el fascículo correspondiente a las Bromeliaceae de la Flora de Veracruz (Espejo et al., 2005) recientemente publicado, incluimos la descripción de una Hechtia que en su momento no fue posible asignar a ninguna de las especies conocidas. Se trata de un nuevo taxon que aquí formalizamos:

Hechtia perotensis I. Ramírez \& Martínez-Correa, sp. nov. (Figs. 4 y 5).

Herbae rosulatae, usque ad 2 m altae, caespitosae; folia permulta, rigida, lamina viridis vel ex purpureo margine maculata, 20-30(50) cm longa, supra glabra, subtus minute lepidota, margine spinas gerens, spinae rectae vel recurvatae, 5-6 $\mathrm{mm}$ longae, brunneae vel atrobrunneae. Inflorescentiae terminales, erectae, bis-ter ramosae, spicae masculinae capituliformes, 2-2.5 cm longae, ca. $1.3 \mathrm{~cm}$ diametro, usque ad tres per nodum; spicae femineae capituliformes, 1.5-3.5 cm longae, ca. 1.9 $\mathrm{cm}$ diametro. Flores masculini virides vel flavo-virides, petala elliptica vel oblonga, 5-7 mm longa, 3-4 mm lata, filamenta linearia, basi dilatata, 4-5 $\mathrm{mm}$ longa, antherae flavae, oblongae, recurvatae, ca. $1.5 \mathrm{~mm}$ longae. Flores feminei virides, petala triangularia, ca. $6 \mathrm{~mm}$ longa, ca. $3 \mathrm{~mm}$ lata. Spicae in fructu capituliformes vel oblongocylindricae, capsula ovoidea, brunnea, nitida.

Hierbas arrosetadas, terrestres, en flor de hasta $2 \mathrm{~m}$ de alto, las rosetas globosas, compactas, de hasta $50 \mathrm{~cm}$ de alto, de $40 \mathrm{~cm}$ de diámetro, densamente cespitosas, con hasta 50 rosetas o más en una colonia, acaules o con tallos inconspicuos. Hojas 


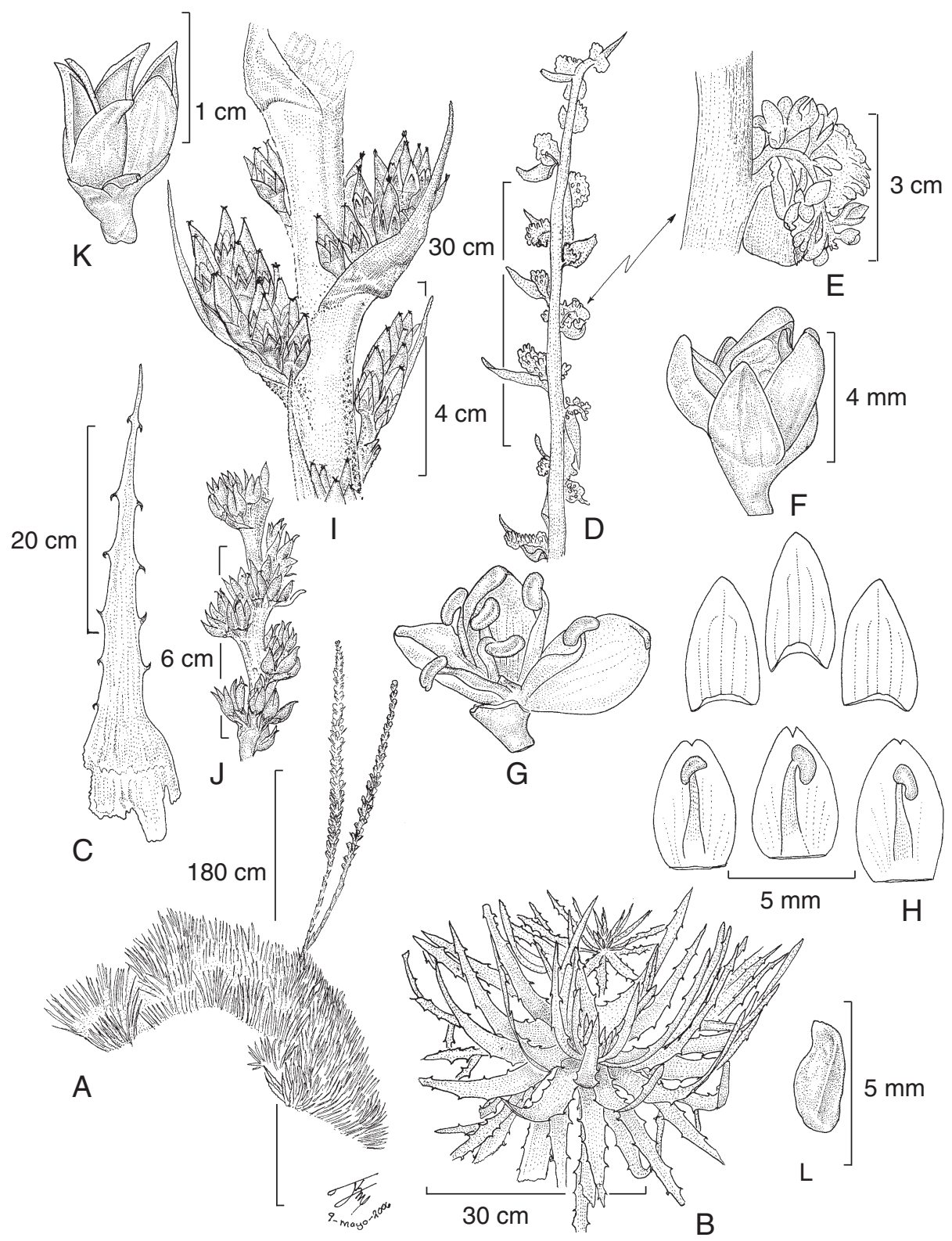

Fig. 4. Hechtia perotensis Ramírez \& Martínez-Correa. A. hábito; B. roseta; C. hoja; D. inflorescencia; E. espiga; F y G. flor; H. flor disecada; I. espigas con frutos jóvenes; J. espigas con frutos maduros; K. cápsula abierta; L. semilla. A-C, I-L plantas femeninas, basado en I. Ramírez-Morillo y C. Durán 1299 y en A. R. López-Ferrari et al. 3109; D-H plantas masculinas, basado en C. H. Ramos 227. 
A

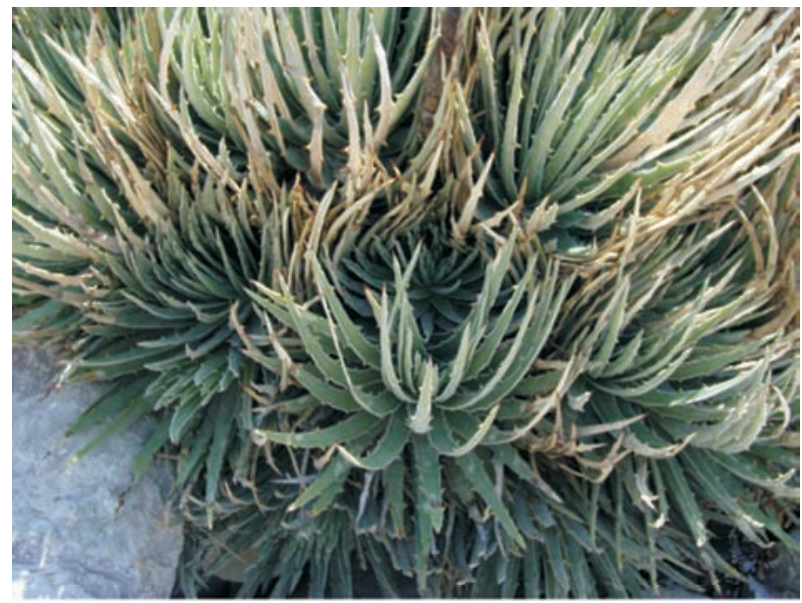

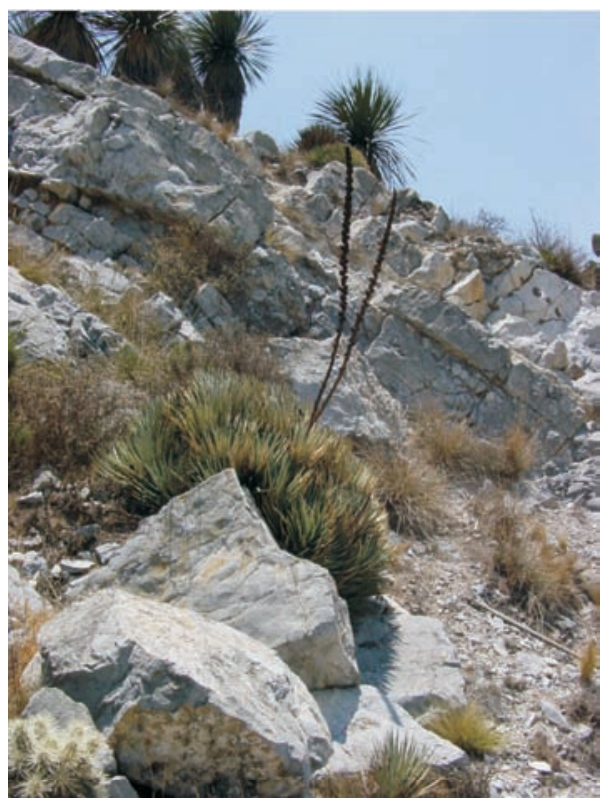

B

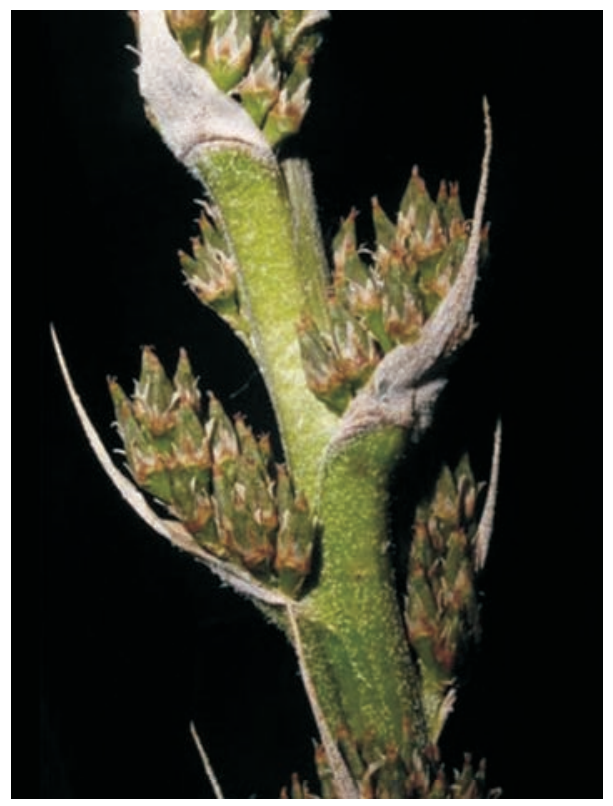

C

Fig. 5. Hechtia perotensis Ramírez \& Martínez-Correa. A y B. hábito; C. espigas con frutos inmaduros. Plantas femeninas, A y B. López-Ferrari et al 3109, fotos A. Espejo; C. I. RamírezMorillo y C. Durán 1299, foto I. Ramírez-Morillo.

numerosas, rígidas, erectas a ascendentes, las vainas pardas, anchamente ovadas a subcuadradas, de 3.5-5.5 cm de largo, de 3.5-5.5 cm de ancho, lustrosas, blancolepidotas hacia la parte apical, las láminas verdes claras, con los márgenes ocasional- 
mente teñidos de rojo, largamente triangulares, de 20-30(50) cm de largo, de 1.5-1.8 cm de ancho, glabrescentes en la haz, diminutamente blanco-lepidotas en el envés, espinosas en el margen, agudas, apiculadas y pungentes en el ápice, las espinas rectas a curvadas, pardas a pardas oscuras, de 5-6 mm de largo, separadas por 1.5-2 cm. Inflorescencias terminales, pero en las rosetas maduras aparentan ser laterales, ya que los retoños se producen en la base de las mismas, erectas, compuestas, paniculadas; las masculinas de 1.2-1.3 $\mathrm{m}$ de alto, 2 veces ramificadas, con numerosas espigas, el escapo cilíndrico, de 30-40 cm de largo, de 2-2.5 cm diámetro; brácteas del escapo pardas, triangulares, de 3-20 cm de largo, de 1.5-3.5 cm de ancho, agudas a acuminadas, las basales densamente imbricadas y mucho más largas que los entrenudos, las apicales más cortas que los entrenudos, las vainas enteras, las láminas erosas a espinosas en el margen, densamente lepidotas en la base en el envés, glabrescentes en la haz, las espigas capituliformes, de $2-2.5 \mathrm{~cm}$ de largo, de ca. $1.3 \mathrm{~cm}$ de diámetro, hasta tres saliendo de un mismo nudo, la espiga central con el raquis más grueso (ca. $2 \mathrm{~mm}$ ) y ligeramente aplanado, las dos laterales con el raquis más delgado (ca. $1 \mathrm{~mm}$ de diámetro) y cilíndrico; brácteas primarias pardas, ovadas a largamente ovadas, papiráceas, de 2.5-7 cm de largo, de 0.8-1 cm de ancho, lepidotas en el envés, erosas, acuminadas, las espigas cortas, de 0.8-3.5 cm de largo; brácteas florales verdes, lanceoladas a oblongas, de ca. $4 \mathrm{~mm}$ de largo; flores polísticas, divaricadas, laxamente dispuestas, numerosas por espiga, actinomorfas, pediceladas, los pedicelos de 2-3 mm de largo; sépalos libres, verdes, ovados a largamente ovados, de 4.5-5 mm de largo, de 2-2.5 mm de ancho, agudos a redondeados en el ápice; pétalos libres, verdes a amarillos, elípticos a oblongos, de 5-7 mm de largo, de 3-4 mm de ancho, redondeados en el ápice; estambres iguales, más cortos que los pétalos, los filamentos lineares, ligeramente ensanchados en la base, de 4-5 mm de largo, las anteras amarillas, oblongas, curvadas, de ca. $1.5 \mathrm{~mm}$ de largo; ovario vestigial, abortivo; las femeninas de ca. $1.6 \mathrm{~m}$ de alto, 2 a 3 veces ramificadas, con numerosas espigas, el escapo cilíndrico, de 15-42 cm de largo, de 1-3 cm de diámetro; brácteas del escapo pardas, largamente triangulares, de 3.5-4 cm de largo, de ca. $1 \mathrm{~cm}$ de ancho, tan largas o ligeramente más largas que los entrenudos, las espigas ascendentes, capituliformes, una por nudo, de 1.5-3.5 cm de largo, de $1.9 \mathrm{~cm}$ de diámetro; brácteas primarias pardas, anchamente triangulares, papiráceas, de $2-5 \mathrm{~cm}$ de largo, de $1-1.3 \mathrm{~cm}$ de ancho, nervadas, agudas a acuminadas; brácteas florales amarillentas, triangulares, de 3-5 $\mathrm{mm}$ de largo; flores polísticas, densamente dispuestas, ascendentes, ca. 20 por espiga, actinomorfas, pediceladas, los pedicelos obcónicos, de 2-4 $\mathrm{mm}$ de largo, de 2.5-3 $\mathrm{mm}$ de diámetro; sépalos anchamente triangulares, agudos y apiculados, de 4-5 $\mathrm{mm}$ de largo; pétalos triangulares, de ca. $6 \mathrm{~mm}$ de largo, de ca. $3 \mathrm{~mm}$ de ancho, agudos; ovario no visto. 
Cápsula parda, lustrosa, ovoide, de ca. $1 \mathrm{~cm}$ de largo, de $7 \mathrm{~mm}$ de diámetro; semillas pardas claras, fusiformes, ligeramente rugosas, de ca. $3 \mathrm{~mm}$ de largo, de $1 \mathrm{~mm}$ de ancho, bicaudadas, con una cauda conspicuamente más larga.

Tipo: México, Puebla, municipio de Aljojuca, laguna de Aljojuca, km 15 carretera federal San Salvador El Seco-Esperanza, 1905'33" N, 97³2'17" W, 2500 m s.n.m., matorral xerófilo en las paredes laterales del cráter, suelo de origen volcánico, 2 mar. 2005. Florecida en cultivo en la ciudad de Mérida, Yucatán, jun. 2005, I. Ramírez Morillo \& C. Durán 1299 (holotipo: CICY (x5); isotipo: UAMIZ (x5), plantas femeninas).

Paratipos: México, Puebla, municipio de Guadalupe Victoria, 6.6 km al SW de Alchichica, ca. $2 \mathrm{~km}$ al SW de la desviación a Techachalco, carretera San Salvador el Seco-Perote, 19²2'10" N, 97²6'15" W, 2390 m s.n.m., A. R. López-Ferrari, A. Espejo y J. Ceja 3109 (UAMIZ(x2), CICY, planta femenina), municipio de Aljojuca, laguna de Aljojuca, $19^{\circ} 05^{\prime 4} 40^{\prime \prime}$ N, 97³2'09" W, 2469 m s.n.m., N. Martínez-Correa, A. Espejo, A. R. López-Ferrari \& J. García Cruz 99 (UAMIZ, planta femenina) 100 (UAMIZ, planta masculina); Veracruz, municipio de Perote, Tenextepec, cerro de Tenextepec, $19^{\circ} 29^{\prime} 6^{\prime \prime}$ N, 97¹5'48" W, G. Castillo et al. 14257 (XAL, planta femenina); Progreso, G. Castillo et al. 18854 (CICY planta femenina); cerros calizos cerca del límite con el estado de Puebla (cerca de Alchichica), C. H. Ramos 227 (MEXU planta masculina).

Distribución y habitat. Hechtia perotensis es endémica de México y se conoce hasta el momento de los estados de Puebla y Veracruz, en donde crece en matorrales xerófilos entre los 2400 y 2500 m s.n.m.

Fenología. Junio-agosto.

Etimología. El epíteto específico hace referencia al área en la cual crece la especie, el Valle de Perote.

Hechtia perotensis pertenece a un grupo de especies que presentan, en las plantas de ambos sexos, las inflorescencias compactas, de 1.5 a $2 \mathrm{~m}$ de largo, con el escapo conspicuo, las ramas cortas y las brácteas primarias generalmente más largas que éstas. 
Lo anteriormente señalado, aunado a la morfología floral que presenta el taxon aquí propuesto, nos llevó a pensar que éste podría asignarse a Hechtia podantha Mez. De acuerdo con el protólogo, el holotipo de $H$. podantha fue depositado en el herbario W, sin embargo, hasta donde sabemos fue destruido durante la segunda guerra mundial. Afortunadamente, en el herbario F existe una fotografía de dicho ejemplar y el análisis de la misma nos permitió concluir que las poblaciones que crecen en la parte centro-oeste de Veracruz y su porción limítrofe con Puebla, en los alrededores de las lagunas de Alchichica y Aljojuca, no corresponden con esta especie. Las ramas de las inflorescencias en el ejemplar tipo de $H$. podantha son mucho más largas que las de $H$. perotensis.

Smith y Downs (1974) y Espejo y López-Ferrari (1994) consideraron a Hechtia tehuacana B. L. Rob. y a H. liebmannii Mez como sinónimos de H. podantha Mez, por lo que pensamos que alguno de estos nombres podría aplicarse a las poblaciones de Perote. Sin embargo, la revisión de los ejemplares tipo y del protólogo de $H$. tehuacana nos permitieron confirmar que dicho nombre pertenece a una especie completamente distinta. Por otra parte, si bien no nos fue posible revisar el material tipo de H. liebmannii, depositado en el herbario C, en el protólogo de la especie (Mez, 1901) se indica que las plantas presentan: "inflorescentia amplissima, laxe tripinnatim panniculata, ramulis elongatis, remote flores gerentibus... ...Folia cum scapo ignota...", características que difieren completamente de las presentes en las inflorescencias compactas con las ramas cortas y las flores densamente dispuestas de $H$. perotensis. Además, en el mismo protólogo se señala que el tipo fue recolectado en Chignautla, Puebla, localidad ahora incluida en los suburbios de Teziutlán. Aunque dicha zona se ubica relativamente cerca del Valle de Perote, presenta condiciones climáticas y de vegetación muy diferentes. Por lo anteriormente expuesto concluimos que el nombre de $H$. liebmannii no puede aplicarse a las poblaciones del taxon aquí propuesto.

\section{AGRADECIMIENTOS}

Deseamos expresar nuestro sincero agradecimiento a Walter Till, Javier García-Cruz y Germán Carnevali por la lectura crítica del trabajo y sus valiosas sugerencias al mismo; a Jacqueline Ceja y Aniceto Mendoza por su constante, desinteresada e invaluable ayuda en el trabajo de campo; a Rolando Jiménez por la elaboración de las ilustraciones de las especies y a los curadores de los herbarios CICY, MEXU, 
UAMIZ y XAL por brindarnos las facilidades para la consulta del material depositado en sus colecciones. Parte de los resultados de este trabajo forman parte de la tesis de Maestría en Biología de la UAM-I de la cuarta autora y fueron financiados gracias al apoyo de CONACyT a través de la beca 202259.

\section{LITERATURA CITADA}

Espejo, A. y A. R. López-Ferrari. 1994. Bromeliaceae. Las monocotiledóneas mexicanas, una sinopsis florística 1. Lista de referencia, parte III. Consejo Nacional de la Flora de México, A.C., Universidad Autónoma Metropolitana-Iztapalapa, Comisión Nacional para el Conocimiento y Uso de la Biodiversidad. México, D.F. pp. 4-50.

Espejo, A., A. R. López-Ferrari e I. Ramírez-Morillo. 2005. Bromeliaceae. Flora de Veracruz. Fascículo 136. Instituto de Ecología, A.C. Xalapa. 307 pp.

Espejo, A., A. R. López-Ferrari, I. Ramírez-Morillo, B. K. Holst, H. E. Luther y W. Till. 2004. Checklist of Mexican Bromeliaceae with notes on species distribution and levels of endemism. Selbyana 25(1): 33-86.

Luther, H. E. 2006. An alphabetical list of bromeliad binomials. Bromeliad Society International. Sarasota, Florida. 119 pp.

Mez, C. 1901. Bromeliaceae et Lauraceae novae vel adhuc non statis cognitae. Bot. Jahrb. Syst. 30 (Beibl. 67): 1-20.

Rzedowski, J. 1991a. Diversidad y orígenes de la flora fanerogámica de México. Acta Bot. Mex. 14: 3-21.

Rzedowski, J. 1991b. El endemismo en la flora fanerogámica mexicana: Una apreciación analítica preliminar. Acta Bot. Mex. 15: 47-64.

Smith, L. B. y R. J. Downs. 1974. Pitcairnioideae (Bromeliaceae). Flora Neotropica. Monograph 14(1): 1-658. 